\title{
Kegiatan Komunikasi Pemasaran dalam Membangun Loyalitas Konsumen Di Cv. Cipta Wahana Kreasi
}

\author{
Jessica Octaviani, Yugih Setyanto \\ Jessica.915150004@stu.untar.ac.id,yugihs@fikom.untar.ac.id \\ Fakultas Ilmu Komunikasi Universitas Tarumanagara
}

\begin{abstract}
Marketing communication is needed by a company, because it can make people know that the company has a product or service, making it easier for consumers who are looking for these products or services. The purpose of this study was to determine marketing communication activities in building consumer loyalty on the CV. Cipta Wahana Kreasi. The right marketing communication can build customer loyalty because customer loyalty is an important factor that becomes a measure of repurchase. This research method uses a type of qualitative research with a case study method conducted on CV. Cipta Wahana Kreasi. Methods of collecting data through interviews, observation, and documentation. The data analysis technique uses qualitative descriptive. The results showed that CV. Cipta Wahana Kreasi only uses two ways of marketing communication, namely only with personal selling, and direct marketing and the company also build customer loyalty in only two of the four types of marketing activities, namely by personalizing marketing and winning back. The implication of this research is that marketing communication by personal selling and direct marketing plays an important role in the company because it is very effective in marketing. In addition, building customer loyalty is also very important because consumers can be loyal to subscribe to the company because of the convenience provided.
\end{abstract}

Keywords: Marketing Communication, Customer Loyalty, Personal Selling, Direct Marketing

\begin{abstract}
Abstrak
Komunikasi pemasaran sangat dibutuhkan oleh suatu perusahaan, karena dapat membuat orang tahu bahwa perusahaan tersebut memiliki produk atau jasa, sehingga memudahkan konsumen yang sedang mencari produk atau jasa tersebut. Tujuan penelitian ini adalah untuk mengetahui kegiatan komunikasi pemasaran dalam membangun loyalitas konsumen di CV. Cipta Wahana Kreasi. Komunikasi pemasaran yang tepat maka dapat membangun loyalitas pelanggan karena Loyalitas pelanggan merupakan faktor penting yang menjadi alat ukur pembelian kembali. Metode penelitian ini menggunakn jenis penelitian kualitatif dengan metode studi kasus yang dilakukan pada CV. Cipta Wahana Kreasi. Metode pengumpulan data dengan wawancara, observasi, dan dokumentasi. Teknik analisis data menggunakan deskriptif kualitatif. Hasil penelitian menunjukkan bahwa CV. Cipta Wahana Kreasi hanya menggunakan dua cara komunikasi pemasaran yaitu hanya dengan personal selling, dan direct marketing dan perusahaan tersebut juga membangun loyalitas pelanggan hanya dua dari empat jenis kegiatan pemasaran, yaitu dengan mempersonalisasikan pemasaran dan memenangkan kembali. Implikasi penelitian ini adalah komunikasi pemasaran dengan cara personal selling dan direct marketing sagat berperan penting di perusahaan karena sangat efektif untuk melakukan pemasaran. Selain itu, membangun loyalitas pelanggan juga sangat penting karena konsumen bisa setia berlangganan di perusahaan tersebut karena kenyamanan yang diberikan.
\end{abstract}

Kata Kunci: Komunikasi Pemasaran, Loyalitas Pelanggan, Personal Selling, Direct Marketing 


\section{Pendahuluan}

Komunikasi pemasaran sangat dibutuhkan oleh suatu perusahaan, dengan adanya suatu komunikasi pemasaran maka dapat membuat orang tahu bahwa perusahaan tersebut memiliki produk atau jasa. Sehingga memudahkan konsumen yang sedang mencari produk atau jasa tersebut.

Komunikasi pemasaran terpadu merupakan suatu proses komunikasi yang memerlukan perencanaan, penciptaan, integrase, dan implementasi dari berbagai bentuk bauran promosi (iklan, direct marketing, Pemasaran interaktif, promosi penjualan, hubungan masyarakat, dan penjualan personal) yang disampaikan dari waktu ke waktu kepada pelanggan dan calon pelanggan. Tujuan dari komunikasi pemasaran terpadu pada akhirnya adalah memengaruhi dengan tidak langsung atau dengan secara langsung perilaku dari audiens yang menjadi target marketing komunikasi. Komunikasi pemasaran terpadu mempertimbangkan semua titik sentuhan, ataupun sumber kontak, yang dimiliki pelanggan atau calon pelanggan dengan merek sebagai saluran penyampaian pesan dan menggunakan semua metode komunikasi yang relevan bagi pelanggan atau calon pelanggan. Komunikasi pemasaran terpadu mensyaratkan semua media komunikasi merek menyampaikan pesan yang konsisten. Proses komunikasi pemasaran selanjutnya mengharuskan bahwa pelanggan / calon pelanggan adalah titik awal untuk menentukan jenis pesan dan media terbaik yang mampu menginformasikan, membujuk, dan mendorong tindakan yang diharapkan. (Shimp, 2014:10).

Pelanggan adalah kunci utama untuk keberlangsungan suatu perusahaan. Pastinya perusahaa memiliki customer lama dan tentunya setiap perusahaan harus mencari atau menarik customer baru untuk menambah pelanggan. Sehingga untuk mencari atau menarik pelanggan baru suatu perusahaan harus melakukan komunikasi pemasaran kepada khalayak agar dapat mengetahui apa yang dimiliki dari perusahaan tersebut.

Surya dan Setiyaningrum (2009) dalam Selang (2013), loyalitas pelanggan merupakan kekuatan hubungan antara sikap relatif individu terhadap suatu kesatuan dan pembelian ulang. Loyalitas pelanggan menekankan pada runtutan pembelian yang dilakukan konsumen seperti proporsi dan probabilitas pembelian. Loyalitas pelanggan merupakan faktor penting yang menjadi alat ukur pembelian kembali. Menurut Kotler dan Keller (2009:153), ada empat jenis kegiatan pemasaran penting yang digunakan perusahaan untuk meningkatkan loyalitas: 1) mengembangkan Program Loyalitas, program frekuensi dan program pemasaran klub merupakan dua program loyalitas pelanggan yang dapat ditawarkan perusahaan. Program frekuensi adalah program yang dirancang untuk memberikan penghargaan kepada pelanggan yang sering membeli dalam jumlah besar. 2) mempersonalisasikan pemasaran, perusahaan dapat menciptakan ikatan yang kuat dengan pelanggan melalui pengindividuan dan personalisasi hubungan. 3) menciptakan ikatan institusional, perusahaan dapat menyuplai pelanggan dengan peralatan khusus atau hubungan computer yang membangun pelanggan mengelola pesanan, penggajian, atau persediaan. 4) memenangkan kembali, perusahaan tidak dapat mencegah beberapa yang tidak aktif atau keluar. Tangtangannya yaitu mengaktifkan kembali pelanggan yang tidak puas melalui strategi pemenangan kembali. Kuncinya adalah menganalisis penyebab keberahlian pelanggan melalui wawancara pada saat pelanggan itu keluar dan survey 
pelanggan yang hilang, dan hanya beusaha memenangkan kembali mereka yang mempunyai potensi laba kuat.

CV. Cipta Wahana Kreasi merupakan perusahaan yang bergerak di bidang garmen. Untuk mencari pelanggan baru, mereka melakukan komunikasi pemasaran dengan cara menyebarkan kartu nama sales dan memperlihatkan sampel produk kepada calon pelanggan, dan biasanya dilakukan di pasar-pasar seperti pasar Tanah Abang, Mangga Dua, dan lain sebagainya.

Rumusan masalah dalam penelitian ini adalah bagaimana kegiatan komunikasi pemasaran dalam membangun loyalitas konsumen di CV. Cipta Wahana Kreasi? sehingga tujuan penelitian ini adalah untuk mengetahui kegiatan komunikasi pemasaran dalam membangun loyalitas konsumen di CV. Cipta Wahana Kreasi.

\section{Metode Penelitian}

Jenis penelitian adalah penelitian kualitatif dengan metode studi kasus. Lokasi penelitian adalah CV. Cipta Wahana Kreasi : Jl. Desa Parigi Mekar Kampung Baru No. 40A, Kecamatan Ciseeng-Bogor dengan periode waktu penelitian 1-31 Mei 2019. Metode pengumpulan data meng unakan observasi, wawancara, dan dokumentasi. Teknik analisis yang digunakan yaitu analisis deskriptif, melalui langkah-langkah penyajian data, reduksi data, dan verifikasi (penarikan kesimpula ).

\section{Hasil Temuan dan Diskusi}

Perusahaan garmen CV. Cipta Wahana Kreasi menggunakan komunikasi pemasaran untuk menarik dan membangun loyalitas dengan konsumen. Komunikasi pemasara yang digunakan antara lain adalah dengan cara personal selling, direct selling, personal selling dengan cara field selling, dan komuikasi pemasaran dengan membangun loyalitas pelanggan.

\section{Personal Selling CV. Cipta Wahana Kreasi}

Kegiatan personal selling CV. Cipta Wahana Kreasi sangat membantu dalam melakukan komunikasi pemasaran yang baik, setiap calon konsumen akan merasa pelayanan suatu perusahaaan baik ketika mendapatkan penjelasan yang detail yang merupakan salah satu peran personal selling.

Berdasarkan hasil wawancara yang dilakukan oleh Tin-Tin selaku customer CV. Cipta Wahana Kreasi :

"menurut saya pelayanan yang diberikan sangat baik dan bertanggung

jawab. Saat menawarkan jasa garmen yang mereka punya juga menjelaskan sangat rinci, jadi saya bisa paham apa aja yang mereka tawarkan, kalau ada yang tidak jelas saya tanyakan lagi ke marketingnya sehingga mereka menjelaskan sampai saya mengerti dan tertarik." (Wawancara dilakukan pada tanggal 19 Juni 2019, di Salad Stop Mall Kelapa Gading 3, pada pukul 13.15 WIB)

Dari wawancara di atas dapat dilihat bahwa peran personal selling sangat dibutuhkan dalam melakukan komunikasi pemasaran kepada calon pelanggan. Karena komunikasi pemasaran dengan cara personal selling lebih efektif dalam menjelaskan 
secara rinci kepada calon konsumen, sehingga konsumen dapat mengerti apa saja yang di pasarkan. Peran personal selling tidak dapat digantikan dengan komunikasi pemasaran yang lain.

Personal selling sangat berperan penting di perusahaan CV. Cipta Wahana Kreasi karena mereka hanya menggunakan komunikasi pemasaran dengan cara personal selling, berdasarkan hasil wawancara dengan Andian selaku marketing di CV. Cipta Wahana Kreasi yang menyatakan :

"Biasanya kita disini pemasarannya dengan bertemu langsung oleh calon customer atau calon konsumen, dan kita memperlihatkan kepada calon customer beberapa contoh atau sample yang dibuat bersama tim dan perusahaan, lalu saya menjelaskan agar meyakinkan customer tentang produk-produk keunggulan perusahaan tempat saaya bekerja melalui contohcontoh yang saya bawa, dan yang terakhir tidak lupa saya kasih kartu nama saya dan perusahaan tempat saya bekerja kepada calon customer." (Wawancara dilakukan pada tanggal 27 Mei 2019, di pabrik CV. Cipta Wahana Kreasi pada pukul $15.30 \mathrm{WIB}$ )

Dan berdasarkan wawancara yang dilakukan oleh penulis dengan Waryudian selaku Direktur Utama CV. Cipta Wahana Kreasi yang menyatakan :

"Menurut saya sih peran personal selling di perusahaan ini sangat berpengaruh ya, soalnya lebih efisien dalam penjualan karena customer lebih mudah tertarik dan dapat di yakinkan dengan jasa garmen yang di tawarkan secara langsung dari marketing kita." (Wawancara dilakukan pada tanggal 27

Mei 2019, di pabrik CV. Cipta Wahana Kreasi pada pukul 14.00 WIB)

Dari kutipan wawancara di atas dapat dilihat perusahaan tersebut hanya menggunakan personal selling sebagai komunikasi pemasaran. Dan peran personal selling di perusahaan CV. Cipta Wahana Kreasi sangat berpengaruh penting untuk mendapatkan calon konsumen, karena dengan pemasaran secara langsung lebih mudah meyakinkan dan menarik konsumen untuk menggunakan jasa garmen mereka. Di CV. Cipta Wahana Kreasi personal selling berjalan dengan sangat baik, sehingga dapat mengembangkan dan membuat CV. Cipta Wahana Kreasi menjadi lebih besar seperti saat ini.

Berdasarkan hasil wawancara dengan Andian selaku marketing di CV. Cipta Wahana Kreasi :

"Kalau menurut saya sih efisien ya, soalnya kan kita bisa menjelaskan lebih detail ke customer. Kalau misalnya kita menjelaskan tidak langsung saya rasa lebih ga detail buat menjelaskan dan meyakinkan customer sih." (Wawancara dilakukan pada tanggal 27 Mei 2019, di pabrik CV. Cipta Wahana Kreasi pada pukul 15.30 WIB)

Dari kutipan wawancara di atas dapat dilihat personal selling lebih efisien, karena marketing dapat menjelaskan secara rinci ketika tatap muka dari pada melalui media social atau secara tidak langsung. Karena kalau menggunakan media social atau secara tidak langsung lebih sulit untuk dapat menjelaskan secara rinci seperti ketika tatap muka.

Dalam buku Komunikasi Pemasaran Terpadu, personal selling dikatakan bahwa suatu bentuk komunikasi langsung antara penjualan dengan calon pembelinya. Dalam hal ini, penjual berupaya untuk membantu atau membujuk calon pembeli untuk membeli produk yang ditawarkan. Penjualan personal melibatkan kontak langsung antara penjual dan pembeli, baik secara tatap muka ataupun melalui melalui alat telekomunikasi seperti telepon. Melalui interaksi secara langsung ini, maka pihak 
penjual dapat melihat dan mendengarkan tanggapan atau respon pembeli. (Morissan, 2010:26). Temuan penelitian di atas sejalan dengan hasil penelitian Abdurahman (2011) bahwa kegiatan komunikasi pemasaran yang efisien yaitu penjualan tatap muka dan promosi penjualan.

\section{Penggunaan Personal Selling Melalui Aktivitas Field Selling}

Dalam melakukan personal selling ada tiga cara yang dapat dilakukan perusahaan untuk pemasara secara langsung, yaitu ada field selling, retail selling, dan executive selling berikut penjelasan dari ketiganya (Priansa, 2017:226).

Di perusahaan CV. Cipta Wahana Kreasi bentuk personal selling yang digunakan hanya dengan cara field selling, yang mengartikan bahwa pemasaran secara langsung yang menyebarkan marketin ke kantor-kantor atau toko-toko calon pelanggan, berdasarkan hasil wawancara yang dilakukan penulis dengan Waryudian selaku Direktur Utama :

"Kita biasanya pemasaran itu cuman menyebarkan marketing ke customer di kantor atau toko, jadi secara langsung gitu pemasarannya, dan biasanya kita kasih masukan-masukan baik dari produk atau produksi ke customer biar lebih paham dan yakin. Kalau di perusahaan kita ga pake pemasaran yang lewat media social." (Wawancara dilakukan pada tanggal 27 Mei 2019, di pabrik CV. Cipta Wahana Kreasi pada pukul 14.00 WIB)

Dan Tin- Tin selaku konsumen dari CV. Cipta Wahana Kreasi mengatakan bahwa secara kebetulan marketing dari perusahaan CV. Cipta Wahana Kreasi mendatangkan toko mereka dan marketing dari perusahaan tersebut menawarkan dan menjelaskan secara rinci keunggulan dari garmen mereka.

Dari kutipan wawancara dan penjelasan di atas dapat dilihat CV. Cipta Wahana Kreasi hanya menggunakan salah satu bentuk personal selling. Dari ketiga bentuk personal selling CV. Cipta Wahana Kreasi hanya menggunakan field selling sebagai bentuk personal selling yang dilakukan dalam perusahaan tersebut. Dimana personal selling dengan bentuk field selling dilakukan dengan cara menyebarkan marketing ke kantor-kantor atau toko-toko calon konsumen.

\section{Direct Marketing CV. Cipta Wahana Kreasi}

Selain personal selling perusahaan CV. Cipta Wahana Kreasi juga melakukan pemasaran dengan cara direct marketing atau pemasaran secara langsung. Menurut Shimp (2000) dalam Chrismardani (2014) pemasaran langsung merupakan bentuk promosi atau pemasaran dengan menggunakan telepon, surat, e-mail, dan alat penghubung nonpersonal lainnya untuk berkomunikasi secara langsung dengan pelanggan dan mendapatkan tanggapan langsung dari pelanggan atau calon pelanggan.

Menurut Shimp (2000) dalam Chrismardani (2014) pemasaran langsung atau direct marketing memberi manfaat kepada pelanggan dengan banyak cara yaitu: kenyamanan pelanggan, memberi calon pelanggan akses dan pilihan produk yang lebih besar, dan membeli menjadi mudah dan bersifat pribadi.

Dan tentunya pemasaran langsung juga memberikan manfaat kepada para penjual, antara lain pemasaran langsung merupakan alat yang ampuh dalam pembentukan hubungan dengan konsumen dan dapat ditentukan waktunya supaya dapat menjangkau calon konsumen pada saat yang tepat. Sejalan dengan penelitian Rachmawati dan Setyanto (2018) bahwa memberikan informasi langsung kepada 
konsumen lebih mendekatkan diri dengan konsumen serta telah memberikan pelayanan kepada konsumen dengan sebaik mungkin dan selalu membangun hubungan yang baik dengan konsumen.

Berdasarkan hasil wawancara yang dilakukan penulis dengan Andian selaku marketing di CV. Cipta Wahana Kreasi :

"Biasanya kita disini pemasarannya dengan bertemu langsung oleh calon customer atau calon konsumen, dan kita memperlihatkan kepada calon customer beberapa contoh atau sample yang dibuat bersama tim dan perusahaan, lalu saya menjelaskan agar meyakinkan customer tentang produk-produk keunggulan perusahaan tempat saaya bekerja melalui contohcontoh yang saya bawa, dan yang terakhir tidak lupa saya kasih kartu nama saya dan perusahaan tempat saya bekerja kepada calon customer." (Wawancara dilakukan pada tanggal 27 Mei 2019, di pabrik CV. Cipta Wahana Kreasi pada pukul 15.30 WIB)

Dari kutipan wawancara di atas CV. Cipta Wahana Kreasi menggunakan pemasaran langsung untuk menawarkan jasa yang mereka miliki. Direct marketing sangat memiliki peran penting dalam pemasaran, sama halnya seperti personal selling.

\section{Membangun Loyalitas Pelanggan Di CV. Cipta Wahana Kreasi}

Setiap perusahaan sangat memperhatikan hubungan dengan konsumen. Salah satu caranya dengan membangun loyalitas pelanggan. Membangun loyalitas pelanggan sangat berdampak positif bagi suatu perusahaan. Karena kenyamanan pelanggan hanya bisa di bangun dengan loyalitas suatu perushaan terhadap konsumen mereka. Surya dan Setiyaningrum (2009) dalam Selang (2013) loyalitas pelanggan sebagai kekuatan hubungan antara sikap relatif individu terhadap suatu kesatuan (merek, jasa, toko, atau pemasok) dan pembelian ulang. Loyalitas pelanggan menekankan pada runtutan pembelian yang dilakukan konsumen seperti proporsi dan probabilitas pembelian. Loyalitas pelanggan merupakan faktor penting yang menjadi alat ukur pembelian kembali.

Ada beberapa jenis kegiatan pemasaran penting yang digunakan perusahaan untuk meningkatkan loyalitas. Menurut Kotler dan Keller (2009:153), ada empat jenis kegiatan pemasaran penting yang digunakan perusahaan untuk meningkatkan loyalitas, yaitu: mengembangkan program loyalitas, mempersonalisasikan pemasaran, menciptakan ikatan institusional, dan memenangkan kembali.

Berdasarkan wawancara yang dilakukan penulis dengan Waryudian selaku Direktur Utama CV. Cipta Wahana Kreasi mengenai membangun loyalitas dengan konsumen:

"Ya setiap perusahaan harus memperhatikan pelayannya, karena kan itu salah satu yang sangat berpengaruh untuk kenyamanan customer. Karena kita bergerak di bidang jasa, yang paling utama untuk di perhatikan itu service, kualitas, dan komunikasi yang dijalani dengan baik harus tetap terjaga." (Wawancara dilakukan pada tanggal 27 Mei 2019, di pabrik CV. Cipta Wahana Kreasi pada pukul 14.00 WIB )

Untuk membangun loyalitas yang baik dengan konsumen Andian menyatakan dalam wawancara :

"Biasanya saya aktif menjalani komunikasi dengan para konsumen, pastinya harus jujur dengan pekanggan kita, merespon setiap kritik dan saran yang diberikan, dan pastinya menjaga kualitas produk atau produksi milik 
konsumen." (Wawancara dilakukan pada tanggal 27 Mei 2019, di pabrik CV.

Cipta Wahana Kreasi pada pukul 15.30 WIB)

Dari pendapat di atas CV. Cipta Wahana Kreasi, dari beberapa jenis kegiatan membangun loyalitas pelanggan perusahaan tersebut menggunakan salah satu jenis kegiatan yaitu mempersonalisasikan pemasaran. Mempersonalisasikan pemasaran adalah perusahaan dapat menciptakan ikatan yang kuat dengan pelanggan melalui pengindividuan dan personalisasi hubungan.

CV. Cipta Wahana Kreasi juga menggunakan salah satu jenis kegiatan membangun loyalitas pelanggan yaitu memenangkan kembali. Memenangkan kembali dapat di artikan perusahaan tidak dapat mencegah beberapa yang tidak aktif atau keluar. Tangtangannya yaitu mengaktifkan kembali pelanggan yang tidak puas melalui strategi pemenangan kembali. Kuncinya adalah menganalisis penyebab keberahlian pelanggan melalui wawancara pada saat pelanggan itu keluar dan survey pelanggan yang hilang, dan hanya berusaha memenangkan kembali mereka yang mempunyai potensi laba kuat.

Adian selaku marketing CV. Cipta Wahana Kreasi mengatakan ada pelanggan yang tidak memesan kembali atau stop order. Namun biasanya ia mendatangkan kembali konsumen yang stop order dan memperlihatkan model-model atau sample terbaru atau juga dengan membuatkan sampel dan model terbaru dengan menggunkana bahan baku millik konsumen yang stop order.

Dari penjelasan di atas bahwa CV. Cipta Wahana Kreasi menerapkan salah satu teori membangun loyalitas pelanggan, yaitu memenangkan kembali. Dimana setiap konsumen yang tidak berlangganan lagi dengan CV. Cipta Wahana Kreasi akan di datangkan kembali oleh marketing dari perusahaan tersebut untuk menawarkan kembali jasa CV. Cipta Wahana Kreasi.

\section{Simpulan}

Dari banyak cara komunikasi pemasaran, CV. Cipta Wahana Kreasi hanya menggunakan dua cara komunikasi pemasaran yaitu hanya dengan personal selling, dan direct marketing dan perusahaan tersebut juga membangun loyalitas pelanggan hanya dua dari empat jenis kegiatan pemasaran, yaitu dengan mempersonalisasikan pemasaran dan memenangkan kembali.

Implikasi penelitian ini adalah komunikasi pemasaran dengan cara personal selling dan direct marketing sagat berperan penting di perusahaan tersebut dan sangat efektif untuk melakukan pemasaran. Selain itu, membangun loyalitas pelanggan juga sangat penting karena menyangkut kenyaman pelanggan. Sehingga dengan membangun loyalitas pelanggan, para konsumen bisa setia berlangganan di perusahaan tersebut karena kenyamanan yang diberikan.

\section{Ucapan Terima Kasih}

Penulis berterima kasih kepada seluruh narasumber atau informan yang bersedia bekerja sama dan memberikan waktu melakukan wawancara guna pengumpulan data. Ucapan terima kasih juga penulis berikan kepada Dosen Fakultas Ilmu Komunikasi Universitas Tarumanagara yang telah memberikan arahan, bimbingan atas terselesaikannya penelitian ini dan terakhir, kepada seluruh rekanrekan teman diskusi di Fakultas Ilmu Komunikasi Universitas Tarumanagara. 


\section{Daftar Pustaka}

Abdurahman, H. R. (2011). Komunikasi Pemasaran Indosiar Dalam Menarik Minat Para Pemasang Iklan Pada Program Keagamaan Bulan Ramadhan. http://repository.uinjkt.ac.id/dspace/handle/123456789/2721

Chrismardani. (2014). Komunikasi Pemasaran Terpadu : Implementasi untuk UMKM. http://kompetensi.trunojoyo.ac.id/neo-bis/article/view/472/442

Kotler dan Keller. (2009). Manajemen Pemasaran. Jakarta : Erlangga.

Morissan. (2010). Periklanan : Komunikasi Pemasara Terpadu. Jakarta : Prenadamedia Group.

Priansa. (2017). Komunikasi Pemasaran Terpadu Pada Era Media Sosial. Bandung : CV Pustaka Setia.

Rachmawati, P. I., dan Setyanto, Y. (2018). Peran Customer Relations Dalam Menerapkan Kebijakan Baru Untuk Membangun Hubungan Yang Baik Dengan Konsumen https://journal.untar.ac.id/index.php/prologia/article/view/1982

Selang. (2013). Bauran Pemasaran (Marketing Mix) Pengaruhnya Terhadap Loyalitas Konsumen Pada Fresh Mart Bahu Mall Manado. https://ejournal.unsrat.ac.id/index.php/emba/article/view/1374/1085

Shimp, A. T. (2014). Komunikasi Pemasaran Terpadu Dalam Periklanan Dan Promosi. Jakarta : Salemba Empat. 